\title{
Gender differentials in the impact of learning styles on metacognitive skills of rural adolescents
}

Gagandeep Kaur, Sarita Saini and Deepika Vig

Received: 19.11.2017; Revised: 29.03.2018; Accepted: 16.04.2018

See end of the paper for authors' affiliations Gagandeep Kaur

Department of Human

Development and Family Studies,

College of Home Science, Punjab Agricultural University, Ludhiana (Punjab) India

Email : gondaragagan07@gmail. com
ABSTRACT : Metacognition has been described as a reaction to one's own cognitive activity. It also encompasses the methods employed to control one's own cognitive processes; and an enlightenment of how one coordinates, plans, and monitors cognitive processes. Where metacognition is "thinking about thinking", learning styles simply represents "thinking about learning". Learning style can be defined as a preferred way of thinking and processing information and it is unique to the learner.Therefore, the current research focusedon exploring the gender differentials in the impact of learning styles on metacognitive skills of rural adolescents. The sample comprised 200 rural school going adolescents (grade $9^{\text {th }}$ and $10^{\text {th }}$ ) drawn from the selected Government Senior Secondary Schools of the randomly selected village of Ludhiana-I Block. The subjects were equally distributed across both the grades ( grade $9^{\text {th }}=100$ and grade $10^{\text {th }}=100$ ) as well as genders (males $=100$ and females $=100)$.VAK Learning Styles Self Assessment Questionnaire (Chislett and Chapman, 2005) and Metacognitive Awareness Inventory (Schraw and Dennison, 1994) were used to collect data.The results indicated that gender had no significant impact on the correlation between metacognition and learning styles of rural adolescents. Further, the sub-component wise analysis of metacognition and learning styles revealed a significantly positive correlation between 'Kinaesthetic learning style' and the 'procedural knowledge', 'conditional knowledge' and 'evaluation' sub-components of metacognition in adolescent boys whereas in girls, a significant positive correlation was found between 'Auditory learning style' and 'conditional knowledge', 'information management strategies' and 'comprehension monitoring' sub- components of metacognition.

KEY WORDS: Metacognition, Learning styles, Procedural knowledge, Conditional knowledge, Evaluation, Information management strategies, Comprehension monitoring

- HOW TO CITE THIS PAPER : Kaur, Gagandeep, Saini, Sarita and Vig, Deepika (2018). Gender differentials in the impact of learning styles on metacognitive skills of rural adolescents. Asian J. Home Sci., 13 (1) : 151-157, DOI: 10.15740/HAS/AJHS/13.1/151-157. Copyright@ 2018: Hind Agri-Horticultural Society. 